\title{
PROBLEMS IN WALNUT BREEDING
}

\section{The Industry in California Being Transformed Through Propagation of Grafted Trees-Walnut Blight and the Variability of the Present Groves-the Ideal Commercial Nut ${ }^{1}$}

\author{
L. D. BATCHELOR \\ University of California Citrus Experiment Station, Riverside, Cal.
}

$\mathrm{T}$ HE walnut industry of California is just entering a transition period, from the planting of seedling groves to the establishment of plantings composed of grafted trees. Just as other seedling fruit trees, such as the orange, apple, peach, almond, etc., have been eliminated, so, too, the seedling walnut groves of California seem doomed to be replaced by clonal varieties. In many ways this industry is as much in its infancy as the apple industry of New York was sixty-five years ago, when varieties first began to be propagated in a commercial way by grafting and budding. This readjustment in the walnut industry is well started, and although it is likely to be gradual in its evolution, and wisely so, the change seems nevertheless certain. There are but a very few seedling trees for sale at the present time by the progressive nurseries, and in fact only a very few such trees have been set out in groves during the past four or five years. This demand for a grafted tree has been brought about largely by the wide range of variation in walnut seedlings, as regards their productivity, commercial value, season of harvest and ability to resist the walnut blight.

With this very recent propagation of the walnut by grafting, which has extended over only ten or twelve years, it is reasonable to expect that the majority of the varieties thus propagated so early in the development of this industry are only partly suited to the needs of the walnut grower. The nuts from many of these grafted varieties fall considerably short of the commercial standard for high-grade walnuts. Some of the heaviest-bearing sorts, such as the Chase, Prolific and El Monte, produce nuts which cannot be sold in the very best grade of the commercial product. On the other hand the Placentia, which produces the most nearly ideal commercial nut, is not a heavy-producing variety, especially in the northern walnut sections, and is quite as susceptible to walnut blight as the average seedling tree. Again, the Eureka variety, which seems successfully to avoid the walnut blight during many seasons by its lateness in coming into bloom, is a very moderate yielding sort in the southern sections. The above examples are only a few of many which might be cited to show the shortcomings of most of the varieties of walnuts now being propagated.

\section{MANY VARIETIES NEEDED}

The wide range of climatic and soil conditions makes the eventual propagation of quite a large number of varieties inevitable. While the coast regions are bathed in fog nearly every morning during the growing season, the inland valleys experience an extremely dry climate with high maximum temperatures. Walnuts are being grown at the present time on soil types varying from the extremes of sand to heavy clay loams. Many of the future varieties must be especially adapted to some one of these particular environments if they are to withstand the test of time.

Many of the present seedling groves are of uncertain origin and represent greatly varying values. No doubt some

1 Read before the twelfth annual meeting of the American Genetic Association, at Berkeley, Cal., August 5. 1915. 
of these groves are the progeny of especially selected trees known to have considerable merit. On the other hand, it is very apparent that many of them are the result of a great demand for seedling trees when this industry was in its infancy twenty or thirty years ago. At that time great quantities of walnuts were planted without due regard for their parentage. Again, there is a wide range of variability among the individual trees of any grove, as variations in type of tree, blooming season, character of foliage, resistance to disease, productivity and character of the nuts.

Type of Tree.-The tree types vary from the upright sturdy individual to the more or less spreading, weeping types, which droop nearly to the ground under the burden of their crop. The upright, vigorous growing type is well exemplified in the Eureka. On the other hand such varieties as the Prolific have a spreading, bushy habit, and an almost semi-dwarfness characterizes their growth.

Blooming Season.-It is not unusual to find the blooming season in an ordinary seedling grove extending over a period of from a month to six weeks. A few individual trees leaf out and blossom with the first signs of spring. Then quite the larger part of the grove comes out in full leaf, while there are frequently trees which are still bare after the nuts on the early individuals are of the size of a marble. This variation in the blooming season has considcrable economic importance in relation to the harvesting and marketing of the nuts as well as the avoidance of diseases and frost which may be more prevalent during certain periods in the spring.

\section{MANY TREES UNPROFITABLE}

Variation in Productivity.-Some of the old experienced walnut growers feel that $25 \%$ of their seedling trees are unprofitable, another $25 \%$ are barely paying expenses, and that the profit is really derived from about $50 \%$ of the trees. The variations in seedling trees is well shown by Smith ${ }^{2}$ in summarizing the results of certain fertilizer tests; he found that twenty trees in a given row varied in productivity as follows: Number of pounds produced by each tree, $1,16,45,10,21,97,20,8,26,0,16,1,18$, $13,10,21,2,31,7,14$. This is only a fair example of the variation in the large majority of seedling groves. The above figures are from a young grove and should not be considered as typical of the total production for twenty mature walnut trees.

Foliage Characters.-The character of the foliage varies from the broad-leaved types, in which case the foliage somewhat resembles that of the horse-chestnut, to the narrow-leaved varieties whose leaves have a tendency to curl up like the foliage of the Winesap apple. The broadleaved types are much more densely foliated and this factor has considerable bearing on the problems of sun-scald on the twigs and trunks of the tree and the exposure of the nuts to this malady. For this reason, the densely foliated varieties may prove best adapted to the inland valleys, where the difficulties of sun-scald are most prevalent. The more sparsely foliated sorts often appear to have less blight on the nuts and leaves, because of their exposure to the sunshine.

Disease Resistance.-Probably one of the most important limiting factors to walnut production in California, and especially in the older walnut sections, is the bacterial disease commonly known as walnut blight. The inroads of this discase have caused a very heavy dropping of the nuts during many seasons of the past, and although a great deal of time and scientific effort have been devoted to the control of this trouble, there is no known means for the prevention of walnut blight at the present time.

The great variation among seedling trees in regard to their susceptibility to blight is indeed a hopeful sign for the eventual production of varieties which will more or less resist this malady. Among 105 trees in an orchard under observation in Orange County, the percentage of diseased nuts on the individual trees before any dropping had

2 Calif. Bull. 231, p. 187, 1912. 


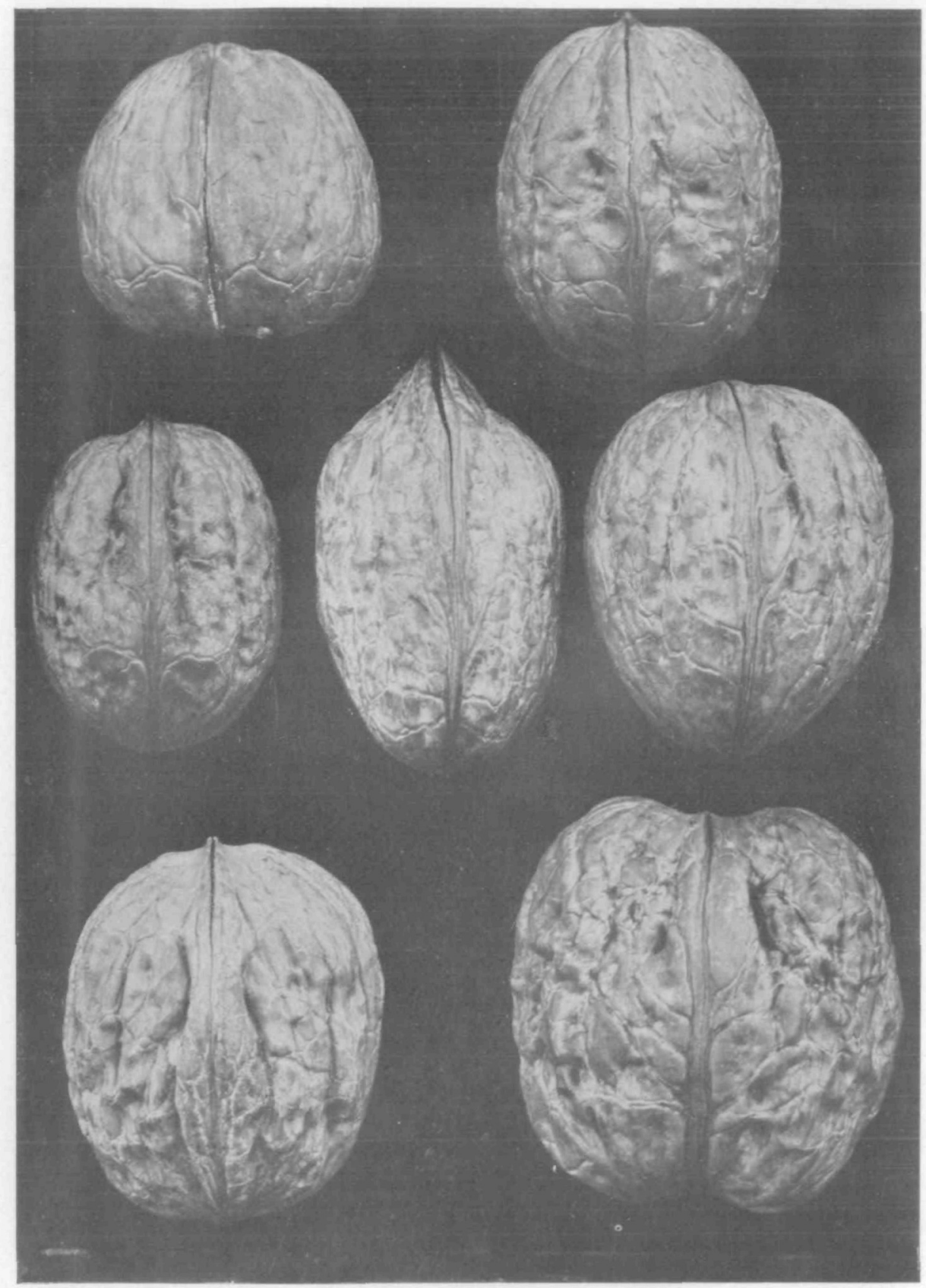

COMMON TYPES OF WALNU'T IN CALIFORNIA

The Persian (commonly called English) walnut is widely grown in California, but as the carly groves were all planted from seed, there are now a great many different types of nuts produced. This illustration shows the wide variation among these types. Efiorts are now being made to organize the industry on a sounder base, by eliminating the worthless types, and introducing new ones which shall combine as many good points as possible. (Fig. 4.) 


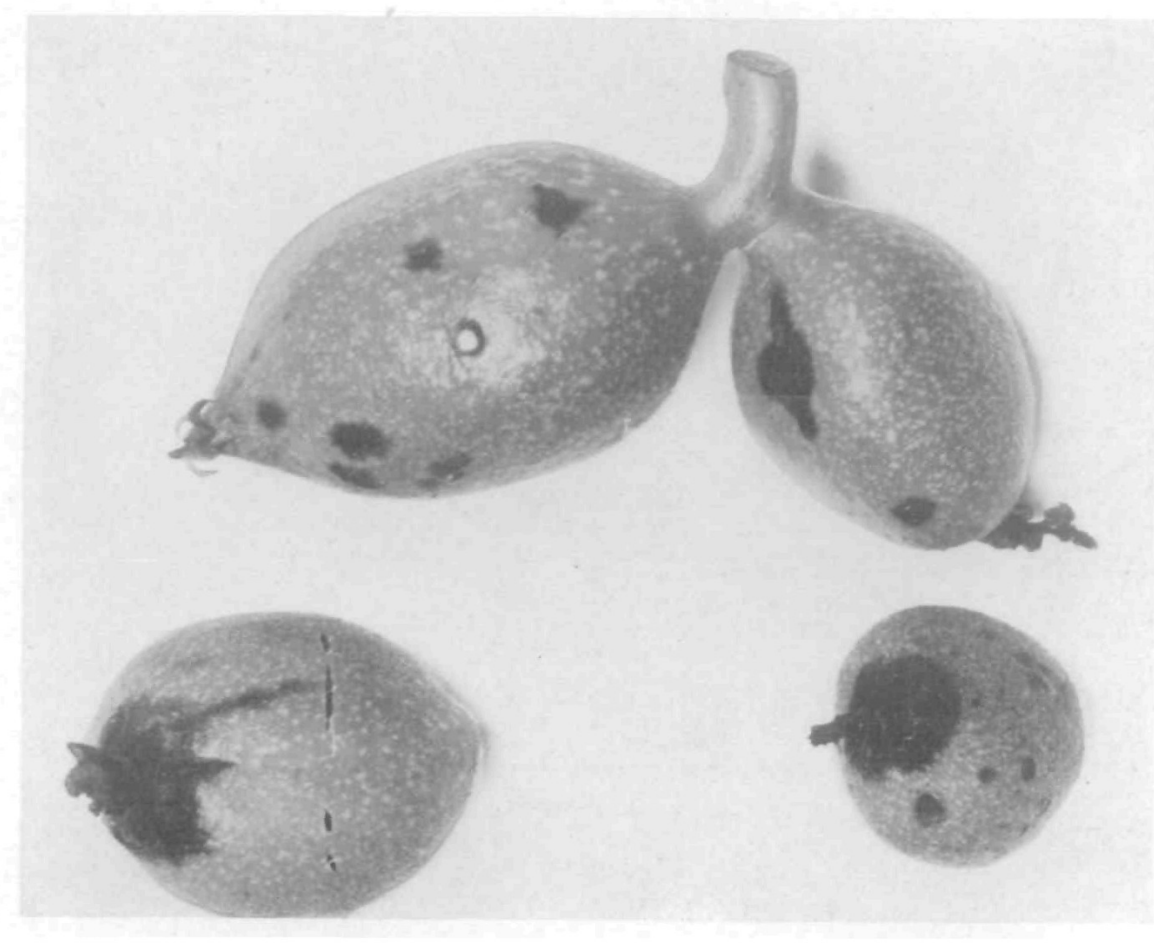

YOUNG WALNUTS AFFLICTED WITH BLIGHT

The walnut industry of California has been seriously threatened by a bacterial disease, against which no remedy has yet bcen found. It has been discovered, however, that great differences exist among individual trees, in their resistance to this infection; and by propagating the most resistant trees, it is believed that groves can be created which will be practically immune to the disease. (Fig. 5.)

taken place, ranged from $6 \%$ to $95 \%$, while the average amounted to $47.4 \%$. These percentages are not given with the idea of expressing the exact amount of injury caused by this disease, as many nuts which are slightly blighted remain on the tree and may yield a commercial product. In calculating the extent of this disease, every nut which was blighted in the least was counted as diseased, and thus the comparisons are thought to be a fair indication of the variation of the blight on the individual trees, but not necessarily an estimate of the damage to the grove. From our present knowlcdge it is very apparent that the disease resistance of individual trees varies considerably from year to year and under different soil and climatic conditions. The thorough testing of resistant varieties will require considerable time.
Nut Characters. - The nuts are as variable as the trees themselves, not only in the exterior appearance but in the character of the meats as well. The ideal commercial nut should be of medium size, as $11 / 8$ to $11 / 2$ inches in diameter, of a regular oval form somewhat elongated, smooth surface, and light brown color, and uniform for these characters. The cracking quality of the nuts is quite as important as their exterior appearance. The nuts should be well sealed so they will not crack open in shipping. The shells should be thin but strong so the nut may be easily opened and the whole meat taken out intact. The pellicle should be light tan colored or silvery brown with a glossy waxed appearance attractive to the eye. The meat should be smooth, filled uniformly throughout the nut, averaging $50 \%$ or more of the total weight, and with a mild, pleasant 


\section{Batchelor: Problems in Walnut Breeding}

flavor free from any astringency. The shells vary from extremely rough and unattractive specimens to smooth commercial types, as the Placentia, while the color of the meats varies from dark brown to nearly white, and so on through the other characteristics mentioned.

In the selection of varieties, the walnut breeder is exceptionally favored by the occurrence of large areas of seedling trees. According to the 1910 census, there were in the neighborhood of one and a quarter million seedling trees growing in California. With this almost unlimited material for selective use, it seems indeed reasonable that many varieties will be selected in the future, which are better adapted to the demands of the industry than some of the walnuts now being propagated. By means of hybridizing methods, it is also hoped that some of the desirable unit characters of the sorts now in cultivation may be re-combined into more nearly ideal varieties for future generations.

Very little is known at present concerning the correlation of certain desirable or undesirable characters of the walnut. Work is under way at present by the Citrus Experiment Station in an endeavor to ascertain these relationships.

The fact that walnut breeding is necessarily a long-termed, expensive problem has made it rather unattractive to the practical breeders. Such work will depend largely upon public institutions for its support.

\section{Plant Breeding at Cornell University}

The plant breeding work at the Cornell University (New York) Experiment Station has given results of both economic and fundamental importance. Among the former are to be noted the production of high-yielding strains of cereals, potatoes, timothies, and so forth. For example, improved strains of oats have been found to yield from 9 to 14 bushels per acre more than the variety from which they were isolated. Two strains of dent corn mature about two weeks earlier than the variety from which they were produced and at the same time outyield somewhat the original variety. The superiority of some of the selected strains of timothy over ordinary timothy has been demonstrated. Hill selection of potatoes has been shown to be an effective method of producing high-yielding strains.

Of the more important fundamental results obtained from the Cornell Station's breeding work may be mentioned the following: Bud variation has been found to occur with no inconsiderable frequency in potatoes and has been demonstrated in clonally-propagated timothies. Results of importance not yet formulated for publication have been obtaincd through studies of seasonal and place variation in daisics. through selection within pure lines of cereals, through hybridization of oat and wheat varieties, and the like. Extensive studies in color inheritance in phlox, morning-glory, beans, corn, and so forth, are being prosecuted, the latter having been recently transferred from the Nebraska Station. Statistical studies of variation also constitute an important part of the plant breeding work at Cornell.

\section{Altering the Galloway Breed of Cattle}

At the Alaska experiment stations, Special Agent C. C. Georgeson writes: "We have made a beginning in the development of an all-purpose cow from the Galloway. Something more is needed in Alaska than the beef qualities, which are so characteristic of the Galloway. The Alaska settler wants a cow that will give milk, as well as produce beef and at the same time be hardy enough to withstand the climate. We expect to reach results by proper mating and selection. It is not contemplated at the present time to go outside of the breed to secure milking qualities, though, undoubtedly, results could be reached more quickly by crossing with some other breed, thereby sacrificing the purity of the stock. The Brown Swiss might make a good cross with the Galloway." 